\title{
PROLEGÔMENOS AO MITO OU SOBRE O FRACASSO DA DEMITOLOGIZAÇÃO
}

Bianka Teixeira de Andrade Silva*

\author{
* biankandrade@gmail.com \\ Mestre em Teoria da Literatura pela Faculdade de Letras da \\ Universidade Federal de Minas Gerais.
}

ABSTRACT: This work problematizes and offers a notion of myth based on Odo Marquard's and mostly Roger Caillois's propositions. With the intention to attest the indispensability of the mython what is the demythologizing method and how it represented a great failure not only to the one who created the method, the theologian Rudolf Bultmann, but also for the entire tendency of thinking that sought to discard the myth through the exacerbated instrumentalization of reaso

KEYWORDS: myth; demythologizing; Caillois; Bultmann.

aquele que o cunhou, o teólogo Rudolf Bultmann, como também através da exacerbada instrumentalização da razão.

PALAVRAS-CHAVE: mito; demitologização; Caillois; Bultmann. 
1. MARQUARD. Abschied vom Prinzipiellen, p. 97. "[...] uma vida miticamente nua, sem historias, Georg Otte).
Da ideia de que "[...] ein mythisch nacktes Leben ohne Geschichten ist nicht möglich"1 apreendemos dois dados importantes para uma das possibilidades de compreensão do mito: o primeiro e com o qual convergiremos instaura sua imprescindibilidade, o segundo refere-se à sua proximidade com a noção de narrativa, este problematizaremos e colocaremos em questão. Assim, nosso percurso aqui conduzirá ao estabelecimento de uma explicação possível sobre o que é o mito, situando-o, antes de tudo, como algo essencial às culturas.

Grandes pensadores, como Friedrich Schlegel, Claude Levi-Strauss e Roland Barthes, dedicaram parte de suas pesquisas à questão do mito. Walter Benjamin e Sigmund Freud parecem ter ido além ao empregarem mitos como fontes de explicação, por exemplo, para a linguagem e para a gênese da moralidade humana; esses casos são emblemáticos em razão não apenas da grande repercussão e reconhecimento que ambos os autores alcançaram, mas sobretudo pelo fato de os mitos, tão desprezados pelas ciências modernas, terem se alinhado ao status de ponto de partida para a elucidação de fenômenos integrantes do homem e da cultura. Freud e Benjamin desviam, então, de etapas importantes do método científico, como a observação e a experimentação, para inserirem mitos como núcleos de suas investigações.
Para além, porém, de pensar sobre os mitos, são ainda mais cruciais e reveladoras as incontáveis práticas deles nas culturas de todos os tempos e espaços de que temos notícia, inclusive e talvez especialmente nas culturas urbanas modernas e contemporâneas - ou, se preferirmos, na cultura globalizada. Em função maiormente dessa perenidade é que a trilha traçada aqui busca perscrutar essa noção.

A compreensão mais comum e difundida do mito localiza-o como história ${ }^{2}$. Segundo o dicionário, ele é "relato fantástico da tradição oral, geralmente protagonizado por seres que encarnam as forças da natureza e os aspectos gerais da condição humana; lenda" e ainda "narrativa acerca dos tempos heroicos, que geralmente guarda um fundo de verdade"3. Concebendo-o assim, pululam facilmente da literatura pontos vários de conexão entre ela e o mito: as épicas clássicas e a literatura fantástica, por exemplo, estariam recheadas de convergências exequíveis para nossa discussão; unidos pela partilha do discurso narrativo e do espaço para a ficção e a fantasia, literatura e mito se imbricariam com naturalidade. Isso facilitaria sobremaneira nosso trajeto, porém, não é como sinônimo de "estória"4 que estabeleceremos a noção alvo deste trabalho.

Apesar de assumirmos tal intenção, escavar outra opção não significa a pretensão de considerá-la assertiva e totalizante, mesmo porque "as tentativas de explicação têm sido
2. A palavra "estória" comporta melhor o sentido de sinonímia que comumente se

3. HOUAISS. Dicionário Houaiss de Língua Portuguesa, p. 1300 (adaptado).

4. Aqui, fazemos alusão à diferenciação entre esse termo e "historia", que propóe esta como a qual a humanidác "em como herança e "estoria" como uma narrativa geralmente ficcional tradicão Inclusive, diante dessa diferencieçã́o e caso estivéssemos convergino mitos por tal caminho, terím mitos por tal caminho, terlamos de apresentar suas afinidades com ambos, ja que a mitologia de um povo pode ganhar representação em suas histórias em suas estórias. 
5. CAILLOIS. O mito e o homem, p. 17.

6. CAILLOIS. O mito e o homem, p. 17-18 (grifos do autor).

7. O teólogo luterano alemão Rudolf Bultmann é considerado o disseminador do método da demitologização que abordaremos em seguida. quase constantemente decepcionantes: o tempo, do mesmo modo que deu origem a diferentes Troias, sobrepôs as camadas das suas ruínas sem o mínimo critério." Atestamos somente seu caráter indispensável, pois

é certo que o mito, que ocupa um lugar no ponto extremo da superestrutura da sociedade e da atividade do espírito, respon de, por natureza, às mais diversas solicitações, e isso simultaneamente, de tal forma que elas se imbricam nele de um modo a priori bastante complexo e que, por conseguinte, a análise de um mito a partir de um sistema de explicação, e por bem fundamentado que ele esteja, deve deixar, e deixa com efeito, uma impressão de insuficiência inultrapassável, um resíduo irredutível a que temos a tentação imediata de atribuir - por reacção - uma importância decisiva. ${ }^{6}$

Destarte, se o mito não cabe num único sistema de explicação, se integra a superestrutura dos povos e se atende a incontáveis solicitações da cultura, é coerente considerá-lo dotado de uma pluralidade incontornável que torna insuficientes todas as tentativas pretensiosas de esgotá-lo. Por essa sua multiplicidade infinda e nuclear, ele aponta que sempre haverá índices de mistério. Por integrar a cultura, aponta que sempre haverá caracteres concretos. Por constituir-se na superestrutura da sociedade, aponta que sempre possuirá uma realidade profunda. E esses três atributos sinalizam a incompletude dos sistemas de explicação, ou correntes teóricas, que precisarão reconhecer um processo de abstração aberto e fragmentado em suas concepções sobre o mito.

Os sistemas de explicação são, portanto, verdadeiros por aquilo que propõem e, inversamente, falsos por aquilo que excluem. Em decorrência disso, um intento totalizante conduz à própria perda do mito, de maneira que um único sistema de explicação não pode atestar exclusividade, pois isso significaria o fracasso do estudo. Nesse sentido, o estudioso francês Roger Caillois critica o ideal de completude presente em pesquisas como as de Freud e Jung, apesar de reconhecer as relevantes contribuições nelas presentes e de incorporar em suas investigações pressupostos que sustentaram teorias desses dois médicos. Ou seja, não são os conteúdos das pesquisas que estão sendo alvo de contestação do sociólogo francês, mas a ambição de abrangência total e monopolizadora que ancoram-nas.

Outra constatação sobre os mitos, além das considerações já colocadas, é que eles vão sendo superados, ou seja, as culturas marcham em direção à morte dos mitos. Não à toa a modernidade recebeu o rótulo de um tempo "demitologizado", mas contra esse enfoque colocaram-se alguns pensadores que discorreram sobre mitos modernos, dentre eles, Roland Barthes em suas Mitologias ${ }^{8}$ e o próprio Caillois em "Paris: mito moderno". Por esse prisma, a morte de determinados mitos não significa o fim dos mitos, pois outros passariam a ser cultivados.
8. Na explanação de Daiane Carneiro Pimentel, como parte no Seminário A Modernidade do Mito, que aconteceu em 2015 no curso de pós-graduac̃ã om Estudos Liteŕrios da UFMG foi mediado pelo Pro foi mediado pelo Prof. Dr. Georg os mitos da socioda mencionou dos anos 1950 cracoñes livro. Segundo livro. " "trando ela, esses mitos pela imprensa como naturais pela imprensa, pela arte e pelo senso comum e seriam fruto de um abuso ideológico que mascara o fato de a realidade ser sempre historicamen interpretada". 
9. CAILLOIS. O mito e o homem, p. 27 (grifos do autor).

10. CAILLOIS. O mito e o homem, p. 27-28.
Contudo, mesmo os mitos mortos projetam suas sombras sobre as sociedades que não mais os cultivam. Uma das razões para isso está nos seus registros, é então que poderemos nos encontrar "em presença de literatura que, deste ponto de vista, seria uma actividade que se substituiria à mitologia quando esta perdesse sua necessidade de ser." Eles não são estórias, não são narrativas, não são literatura, mas nelas podem ser guardados e transmitidos; por meio delas tomamos contato com mitologias que se perderiam e conseguimos, então, "reencontrar a trama da sua organização e, por esta via [...], as determinações inconscientes da afectividade humana".

Já temos algumas pistas que nos conduzem a uma noção de mito. À continuação, proporemos mais algumas e apresentaremos como exemplo o mito de Paris.

A literatura da antiguidade clássica conta-nos sobre os mitos vividos naquela cultura. De maneira deficiente - por valer-se do meio limitado implicado na narrativa -, epopeias como Eneida e Ilíada colocam-nos diante do modo de organização dos povos nelas representados e de seus mitos. Disseminou-se na modernidade conjecturas que propunham a demitologização da cultura em função de uma crença na acentuada instrumentalização da razão como potência libertadora dos instintos humanos. Essa própria crença denuncia-se ao instituir também diversos mitos que colocaram a civilização em marcha rumo a eles. O progressismo, o positivismo e o cientificismo são doutrinas racionalistas que exemplificam isso, de tal forma que a desconstrução e o malogro de muitas de suas propostas resultaram num processo de desencantamento e apatia social que ainda lança sobre nós suas consequências. Provavelmente, não foi menos impactante para as civilizações greco-romanas desvencilharem-se de seus mitos. Como propõe Marquard no seu "Lob des Polytheismus" ${ }^{\prime 1}$, isso nos revela que as culturas jamais despiram-se deles. E, em torno da questão, podemos sugerir duas direções para a existência dos mitos: uma de tendência mais material, sensível e outra de tendência mais formal, racional.

Marquard também, como vimos anteriormente neste trabalho, atesta que "Mythen sind - ganz elementar - justament dieses: Geschichten. Man mag sagen: Ein Mythos ist fiktiver als eine 'history' und realer als eine 'story'; aber das ändert nichts am Grundbefund: Mythen sind Geschichten" ${ }^{12}$ É esse ponto que tentamos desconstruir, sugerindo que mitos não são linguagem, histórias, estórias, explicações ou narrativas, mas nestas eles ganham, deficitariamente, representações se expressam, se preservam ainda que de forma inacabada.

Os mitos são certos fundamentos capazes de refletir um mesmo pensamento em meios diferentes, devido a isso, sua estrutura comporta uma organização perspectiva através de diversos extratos de afetividade, ou seja, eles têm um potencial suavizador capaz de adentrar os diversos sujeitos de
11. MAROUARD. Abschied vom Prinzipiellen, p. 97.
EM TESE
BELO HORIZONTE
N. 2
MAIO-AGO. 2016
12. MARQUARD. Abschied vom Prinzipiellen, p. 93. “De um modo elementar, os mitos são histórias. Pode-se dizer que um mito é mais ficcional que uma history e mais real que uma story mas isso não muda nada na constatação fundamental de os mitos serem histórias" (Tradução de Georg Otte). 
uma sociedade, o que os tornam propensos à disseminação coletiva. Assim, as culturas os assumem em suas estruturas e, por determinado tempo, eles constituem fundamentos dificilmente colocados em questão e, por isso, naturalmente assimilados e apropriados como verdades.

Nesse ponto se reforça a diferenciação entre o mito e a literatura, posto que a obra literária se conecta ao indivíduo por meio de simpatias e afinidades de tendências, portanto ela favorece a existência subjetiva. Em contraposição, o mito favorece a existência coletiva, uma vez que justifica, apoia e inspira a organização e a ação de uma comunidade; ele é dogmático enquanto a literatura propõe sem constranger. Quando o mito perde seu poder moral, de constrangimento, pode vir a se tornar literatura, objeto estético.

Esse caráter dogmático talvez tenha ganhado uma faceta mais velada a partir da modernidade, pois, em períodos anteriores, a incitação à crença e à obediência nos mitos pode ser considerada mais explícita e legitimada declaradamente por instâncias que detinham o poder social, como a Igreja e o Estado.

Como exemplo, a força das representações da cidade de Paris acabou empreendendo um caminho da literatura em direção ao mito. Num contexto de democratização da leitura e de reprodutibilidade em larga escala, como era o de Paris no século XIX, as expressões da cidade em obras literárias, especialmente as de Balzac e Baudelaire, saltaram da arte para a crença massiva da sociedade, pontes foram erigidas entre a representação literária desse espaço urbano e a vida efetiva da cidade. A vida urbana, como no próprio pensamento de Baudelaire sobre a modernidade, alcançou uma dimensão mítica e muitos fatos históricos confirmam a adesão social a isso.

Nas conjecturas de Caillois, Paris é tida como um mito moderno porque, assim como os mitos, a representação dessa cidade guarda, concomitantemente, uma certa força de constrangimento e uma pluralidade de ressonâncias. Processos semelhantes ocorreram nas cidades brasileiras do Rio de Janeiro e Belo Horizonte, por exemplo. Obras como as de João do Rio e de Pedro Nava são, respectivamente, reveladoras das crenças nas ideologias da modernidade e seus mitos observadas no processo de constituição dessas duas cidades. ${ }^{13}$

Tendo em vista esses exemplos e devido ao caminho que construímos até aqui, podemos situar a noção de mito como uma estrutura constituída por dois sistemas de fabulação: uma espécie de concentração vertical e uma espécie de concentração horizontal. A primeira se liga ao poder de constrangimento subjetivo e ao apelo produzido na formação e no modo de pensar dos sujeitos, a segunda refere-se à atitude afirmativa gerada devido a essa força de convencimento e à interconexão que produz uma forte mobilização coletiva,
13. Essas informações foram contribuições dos colegas do Mito (este, já citado noutra nota), Tiago Padilha de Holanda, que expôs sobre João do Rio e seu livro $A$ alma encantadora das ruas, e Denise Frade, que belo-horizontina e seus reflexos nas obras de escritores como Carlos Drummond de Andrade, Fernando Sabino, Paulo Mendes Campos, Otto Lara Resende, Hélio Pellegrino e o próprio Pedro Nava. 
14. CAILLOIS. O mito e o homem, p. 25. projetando o poder dos mitos para toda uma cultura. Ambas são tramas complementares cujas interferências possuem relativa liberdade.

Mas, para assentirmos no que acabamos de afirmar, torna-se necessário compreendermos o que é a fabulação e qua a sua "função". A função fabulatória fomentaria os mitos e teria como "utilidade" o fato de "a plurivocidade da projeção mítica de um conflito permitir uma multiplicidade de ressonâncias que, tornando-o perturbante, simultaneamente, sob diversos aspectos, faz dele aquilo que parece ser de início: uma força de investimento da sensibilidade”. ${ }^{14}$ Desse modo, ao preservar a multiplicidade, a fabulação resguarda a margem para a individualidade ao mesmo tempo em que resguarda o potencial de disseminação coletiva.

É muito importante inserirmos nos prolegômenos aqui explanados sobre o mito o teor compensatório e a dependência humana de sua existência, pois, conforme indica Caillois, a natureza apresenta comportamentos, os homens, além destes, apresentam mitologias. Portanto, a representação mítica se destina a provocar, na ausência do puro instinto, o comportamento que seria desencadeado por ele. Por esse ângulo, mesmo os mitos modernos seriam aqui contemplados, pois possuem forças de constrangimento, muitas vezes implícitas, que conduzem a humanidade à busca de um comportamento natural, ao encontro com um modo de vida mais suficiente.
Nesse viés, mitos constituem-se de conteúdos subjacentes necessitados de corporeidade, são estruturas potenciais que "clamam" por tangibilidade, estas nos são subtraídas em decorrência das intangibilidades com as quais nos encontramos nos territórios da abstração. As manifestações incompletas e os apelos dos mitos atestam sua indispensabilidade entre os povos. Por isso, a cultura não vive sem mitos. Instrumentalizar a razão e consentir em sua existência pura foi e é o mito de acreditar na superação dos mitos.

Talvez, o caso mais emblemático e deliberado dessa frustrada empreitada seja a instauração do método da demitologização, concebido e empreendido por Rudolf Bultmann (1884-1976) em sua malograda tarefa de limpar a religião cristã de seus mitos.

Exatos dois meses antes de a Alemanha Nazista invadir a União Soviética, iniciando a Batalha de Moscou, uma das mais sangrentas ocorridas na Segunda Guerra Mundial: esse contexto histórico contado entre os mais catastróficos enfrentados pela humanidade é o momento no qual o teólogo e professor luterano alemão Bultmann proferiu sua palestra "Revelação e acontecimento salvífico" ${ }^{15}$, que posteriormente recebeu o nome de "Novo testamento e mitologia: o problema da demitologização da proclamação neotestamentária". Em suas palavras, registraram-se conjecturas que escandalizaram os religiosos de seu tempo por instaurarem a premissa
15. BULTMANN, Rufolf. Offenbarung und Heilsgeschehen. München: Chr. Kaiser, 1941. 
16. BULTMANN. Demitologização, p. 05

17. BULTMANN. Demitologização, p. 07 . de que a interpretação mitológica do Novo Testamento era um grave problema.

Como os pensadores de seu tempo buscavam perscrutar o mundo pela via do método científico moderno, tornou-se uma grande incoerência as concepções míticas que se extraem do Novo Testamento. Nelas, por exemplo, "O universo é considerado como dividido em três andares. No meio se encontra a terra, sobre ela o céu, abaixo dela o mundo inferior" ${ }^{16}$, porém

[...] a concepção do universo pode se alterar devido à descoberta copernicana ou em consequência da teoria atômica. Ou então quando o romantismo descobre que o sujeito humano é mais complicado e mais rico do que poderia ser compreendido através da cosmovisão do iluminismo e do idealismo. ${ }^{17}$

Desse modo, o teólogo demonstra assentir na situação de anacronia na qual se encontravam as religiões cristãs, fato que fica evidente em sua pergunta:

A proclamação cristã pode esperar do ser humano de hoje que aceite como verídica a concepção mítica de universo? Isso é sem sentido e impossível. Sem sentido, pois a concepção mítica do universo não é, como tal, nada especificamente cristã, mas é simplesmente a concepção do universo de uma época passada, ainda não moldada pelo pensamento científico. Impossível, pois uma concepção do universo não é algo de que se possa apropriar-se mediante uma resolução, mas já está configurada para o ser humano junto com sua respectiva situação histórica. Naturalmente, ela não é imutável, e também o indivíduo pode contribuir para sua transformação. [...] [Portanto,] é impossível restabelecer a concepção mítica do universo depois que o pensamento de nós todos foi irrecorrivelmente moldado pela ciência. ${ }^{18}$

Assumindo esse choque entre os paradigmas vigentes e a profissão de fé das religiões cristãs, Bultmann promove uma tentativa de transformar essa colisão em parceria, conduzindo o cristianismo por uma via paralela à que caminhava o pensamento moderno. Essa parceria une filosofia e teologia, especialmente através das aproximações feitas pelo teólogo entre a religião e as ideias de Heidegger (1889-1976) ${ }^{19}$, este, um dos alicerces de suas colocações na palestra "Novo testamento e mitologia: o problema de demitologização da proclamação neotestamentária”.

Para legitimar sua posição, o professor lança mão, sobretudo, de três argumentos: primeiro, a falácia de que Cristo retornaria em breve, conforme profetiza o Novo Testamento. Em seguida, o próprio pensamento de Heidegger como via de ratificar a aproximação que promove entre teologia e
18. BULTMANN Demitologização, p. 07 (grifos do autor)

\section{Os três textos desse autor} Fenomenologia da vida religiosa - "Introdução à fenomenologia da religião", "Agostinho e o neoplatonismo" e "Os mística medieval" - são parte mistica medieval" - são parte feita por Bultmann em seus estudos sobre a demitologização. Desse modo, nota-se que 0 teólogo busca em Heideg teólogo busca em Heidegger proposta. 
20. BULTMANN. Demitologização, p. filosofia, tão mal vista por representantes de ambos os lados, que geralmente compreendem fé e razão como territórios reciprocamente impenetráveis. E, por fim, o fato de o homem moderno ter se libertado das forças misteriosas que 0 subjugavam a uma condição passiva e impessoal que aguarda e se entrega imperturbável à atuação do destino e de Deus.

Justamente em sua visão do homem como ser ativo que volta a si mesmo e sai da perdição da impessoalidade é que a filosofia de Heidegger torna-se profícua para as colocações de Bultmann, que combatem o passivismo apreendido das interpretações do Novo Testamento, em passagens, por exemplo, como a de $1^{\text {a }}$ Coríntios, capítulo 4, versículo 7: "Que tens tu que não tenhas recebido? E, se o recebeste, por que te vanglorias, como se o não tiveras recebido?"

Do que está exposto até aqui, uma indagação é tentadora: o que restou do cristianismo no pensamento do teólogo alemão? Segundo ele, tudo que torna ainda significativa e legítima a profissão de sua fé: o fato de Jesus Cristo - filho de Deus, ser divino preexistente e, portanto, uma figura mítica - ser também Jesus de Nazaré, um homem histórico que foi crucificado e, em função disso, comprova que "o acontecimento salvífico [...] não é um acontecimento miraculoso, supranatural, mas um acontecimento histórico no espaço no tempo" ${ }^{20}$, ou seja, a legitimidade do cristianismo estaria na existência factual de Jesus.
Tais pressupostos de Rudolf Bultmann ilustram sua compreensão do que é o mito e do que é a noção de demitologização que ele mesmo cunhou. As acepções do dicionário guardam grande proximidade com o que nos conta o professor ao somarem às duas concepções explanadas no princípio deste estudo as explicações do mito como

[...] 3 relato simbólico passado de geração em geração dentro de um grupo, que narra e explica a origem de determinado fenômeno, ser vivo, instituição costume social; 4 representação de fatos e/ou personagens históricos, amplificados através do imaginário coletivo e de longas tradições literárias orais ou escritas; 5 exposição alegórica de uma ideia qualquer, de uma doutrina ou teoria filosófica [...]; 6 representação idealizada do estado da humanidade, no passado ou no futuro. ${ }^{21}$

Muitas histórias transmitidas do Novo Testamento poderiam tranquilamente exemplificar essas acepções de mito: a passagem na qual Jesus expulsa os espíritos malignos de um homem colocando-os numa manada de porcos ${ }^{22}$ seria um relato fantástico, uma lenda. O socorro prestado por Jesus à mulher adúltera a qual os fariseus queriam apedrejar ${ }^{23}$ seria uma narrativa de um acontecimento heroico. $\mathrm{O}$ batismo de Jesus por João Batista ${ }^{24}$ e as várias parábolas seriam relatos simbólicos passados de geração em geração. A figura de Cristo como filho de Deus seria, talvez, a mais emblemática
21. HOUAISS. Dicionário Houaiss de Língua Portuguesa, p. 1300.

22. Evangelho de Marcos 5: 1-14

23. Evangelho de João 8: 1-11.

24. Evangelho de João 1: 32-34. 
25. BULTMANN. Rudolf. Zum Problem der Entmythologisierung. In: BARTSCH, Hans Werner (Org.). Kerygma und Mythos. Hamburg: Reich \& Heidrich Evangelischer Verlag, 1952. 177-208. representação do Ocidente de um personagem histórico, amplificada pelo imaginário coletivo. Outrossim, a narrativa do retorno de Jesus seria a mais relevante do Ocidente como representação idealizada do estado da humanidade no futuro. Enfim, as passagens do Novo Testamento que ilustram essas acepções de mito do dicionário e estão em consonância com a proposta de Bultmann são inúmeras.

Destarte, apesar de o teólogo não explicitar objetivamente sua noção de mito, é possível apreendê-la diluída em seus textos "Novo testamento e mitologia: o problema da demitologização da proclamação neotestamentária" e "O problema da demitologização" ${ }^{25}$ como a matéria-prima da qual se extraem os relatos sobrenaturais que põem o homem numa situação de observador passivo e insciente, pois

Encontra expressão no mito a crença de que o mundo conhecido e disponível, em que vive o ser humano, não possui em si mesmo fundamento e alvo, mas que contrariamente, seu fundamento e seu limite residem fora da esfera do conhecido e do disponível. Ademais, se expressa nele a crença de que tudo quanto é conhecido e disponível é permanentemente permeado e ameaçado pelos sinistros poderes que lhe são fundamento e limite. Finalmente, junto com os dois aspectos expostos, o mito dá expressão ao conhecimento de que o ser humano não é senhor de si mesmo, de que é dependente não apenas dentro do mundo conhecido, mas dependente sobretudo daqueles poderes atuantes além da esfera do conhecido $[\ldots]^{26}$

Quanto à demitologização, essa terminologia aparece também diluída na palestra de 1941, "Novo testamento e mitologia”, mas é circunscrita no ensaio publicado em 1952 "O problema da demitologização" e já conta com entrada no dicionário brasileiro Houaiss ${ }^{27}$. Bultmann propõe-na como o método "hermenêutico que interroga enunciados ou textos mitológicos quanto a seu teor de verdade" ${ }^{28}$ Ele elucida ainda mais essa sua noção ao diferenciar a tarefa da ciência natural da tarefa da ciência histórica, esta interpreta os mitos extraindo deles os acontecimentos históricos, enquanto aquela simplesmente os descarta. ${ }^{29}$ Demitologizar significa, desse modo, limpar os enunciados míticos dos próprios mitos, desnudando o teor de verdade. Por esse prisma, os mitos se constituiriam dos invólucros dentro dos quais estariam guardados os núcleos de verdade. Tais invólucros seriam, por fim, o lixo resultante da aplicação do procedimento de demitologização.

Mesmo tendo sido aqui confrontado em sua assertiva de que mitos são histórias, cabe reforçar a importante contribuição de Odo Marquard, que segue noutra direção e por isso acaba por tornar a cultura em qualquer de suas esferas, para além da religiosa, imune ao método da
26. BULTMANN. Demitologização, p.

7. Método interpretativo que empreende uma eliminação dos aspectos mitológicos dos textos bíblicos, explicados doravante na perspectiva de uma religiosidade mesclada a indagações filosóficas; demitificação. Desenvolveu-se especialmente na teologia protestante a partir da obra de R. Bultmann. (HOUAISS. Dicionário Houaiss de Língua Portuguesa, p. 612.)

28. BULTMANN. Demitologização, p. 91 (grifos do autor).

29. BULTMANN. Demitologização, p.
EM TESE
BELO HORIZONTE
v. 22
N. 2
MAIO-AGO. 2016
SILVA. Prolegômenos ao mito ou sobre o fracasso da demitologização
P. $33-43$ 
30. MARQUARD. Abschied vom Prinzipiellen, p. 93. "A meu ver, a história da demitologização é, ela mesma, um mito; e a transformação da morte do mito em mito mostra um pouco sua relativa imortalidade. É pelo menos um indício de que não conseguimos existir sem o mito" (Tradução de Georg Otte).

31. MARQUARD. Abschied vom Prinzipiellen, p. 97. "As pessoas são devedoras dos mitos [ Abolir os mitos: sem chance" (Tradução de Georg Otte).

32. As estéticas naturalista e realista, por exemplo, tanto nas artes plásticas quanto na literatura, aproximacão com a ciência una através de princípios como mpiri e a fidelida cono a (a) demitologizar o campo artístico, ão da incorporação da tradição aro da-roman ma do mito greco-romana, mas do mito contrapõ unidace que se contrapoe ao logos. Fáo e que cis vertén, a conviver com continaram

a conviver com expressoes esteticas de principios diferentes mesmo opostos. demitologização. Segundo ele, há que se duvidar do striptease dos mitos, uma vez que "Diese Geschichte des Prozesses der Entmytholodisierung ist - meine ich - selber ein Mythos; und dass so der Todd es Mythos selber zum Mythos wird, beweist ein wenig des Mythos relative Unsterblichkeit". ${ }^{30}$ "Menschen sind mythenpflichtig [...]. Die Mythen abzuschaften: das ist aussichtslos". ${ }^{31}$

A julgar por como as religiões cristãs contemporâneas narram e conduzem sua profissão de fé, o método de Bultmann foi um fracasso. Somemos a isso o fato de haver um bom número de pensadores na contracorrente, dentre os quais, este trio de compatrícios e quase contemporâneos do teólogo - já aqui mencionados: Walter Benjamin (1892-1840), que valeu-se de um mito bíblico para teorizar sobre a linguagem o fundador da psicanálise, Sigmund Freud (1856-1939), que alicerçou seu pensamento em mitos como o parricídio original e a narrativa grega de édipo; e Odo Marquard (19282015). Acrescentemos, ademais, a constatação de que outras esferas da cultura empreenderam projetos para se desvencilharem dos mitos, como a ciência e até mesmo a $\operatorname{arte}^{32}$, e também perderam fôlego.

Em vista disso, os mitos que a modernidade tentou jogar no lixo, talvez, sejam agora substâncias pútridas a incomodar as ilusórias verdades que a humanidade conquistou. No intuito de instaurar um jogo de reflexos com essa propositura da impossibilidade de uma existência "amítica", ilustramo-la por meio deste poema:

\section{Sensação}

Vejo cantar o pássaro

toco este canto com meus nervo

seu gosto de mel. Sua forma

gerando-se da ave

como aroma.

Vejo cantar o pássaro e através

da percepção mais densa

ouço abrir-se a distância

como rosa

em silêncio ${ }^{33}$

33. FONTELA. Poesia reunida, p. 52.

EM TESE

BELO HORIZONTE

v. 22

N. 2

MAIO-AG0. 2016

SILVA. Prolegômenos ao mito ou sobre o fracasso da demitologização

P. $33-43$ à abstração: ver o canto implica apreciá-lo com olhos, tocar o canto com os nervos envolve a sensação tátil, provar o gosto de mel do canto é submetê-lo a uma sensação gustativa, o aroma envolve a apreciação olfativa e o próprio canto do pássaro remete à audição. Por fim, a forma do canto é o que projetamos na abstração. Desse modo, a percepção mais densa da segunda estrofe é essa que envolve todos os sentidos

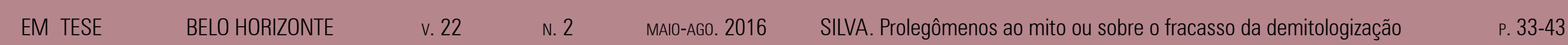


e também a forma; seria ela, para o homem, a completude, a corporeidade total, mas a distância se abre em silêncio, o canto do pássaro se dissipa antes da concretização da percepção em toda a sua densidade.

Finalizamos com esse texto literário na tentativa de promover uma poética analogia entre ele e os prolegômenos ao mito que buscamos circunscrever quando o colocamos como o conteúdo subjacente que apela por corporeidade. Se isso é o mito, torna-se possível assenti-lo como parte determinante das culturas humanas, ao ponto de, mesmo quando deixa de existir, passar a integrar as estórias e os sistemas de explicação, neles ganhando representação. Situamo-nos, portanto, numa conjuntura sempre salpicada por dimensões míticas e, se assim for, os mitos jamais morrerão.

\section{REFERÊNCIAS}

BÍBLIA. Português. A Bíblia da Mulher. Trad. João Ferreira de Almeida. São Paulo: Mundo Cristão; Barueri: Sociedade Bíblica do Brasil, 2003.

BULTMANN, Rudolf. Demitologização: coletânea de ensaios. 2 ed. Trad. Walter Altmann: Luís Sander. São Leopoldo 1999.

CAILLOIS, Roger. O mito e o homem. Trad. José Calisto dos Santos. Lisboa: Edições 70, [1972].

FONTELA, Orides. Poesia reunida. São Paulo: Cosac Naify; Rio de Janeiro: 7Letras, 2006.
HOUAISS, Antônio; VILLAR, Mauro Salles. Dicionario Houaiss da Língua Portuguesa. Rio de Janeiro: Objetiva, 2009.

MAROUARD, Odo. Lob des Polytheismus. In:

Abschied vom Prinzipiellen. Stuttgart: Reclam, 1991. p. 91-116. 